\title{
Free Testosterone to Testosterone Ratio Measurement
}

National Cancer Institute

\section{Source}

National Cancer Institute. Free Testosterone to Testosterone Ratio Measurement. NCI

Thesaurus. Code C147439.

The determination of the ratio of free testosterone compared to total testosterone present in a sample. The measurement may be expressed as a ratio or percentage. 